\title{
Antecedents of Using Financial Software Applications on MSME Sustainability in Banyumas Regency during the Covid-19 Pandemic
}

\author{
PRIMASARI, Dona*; HERWIYANTI, Eliada; WIDIANINGSIH, Rini; LESTARI, Puji \\ Accounting Department, University of Jenderal Soedirman, Purwokerto, Indonesia. \\ *Corresponding author (dona_primasari@yahoo.com)
}

PUBLISHED: 23/12/2021

\section{COPYRIGHT NOTICE:}

(C) 2021 by authors. Licensee ERUDITUS. This article is an open access article distributed under the terms and conditions of the Creative Commons Attribution (CC BY) license (https://creativecommons.org/licenses/by/4.0/).

\section{CITE THIS PAPER:}

Primasari, Dona; Herwiyanti, Eliada; Widianingsih, Rini; Lestari, Puji (2021). "Antecedents of Using Financial Software Applications on MSME Sustainability in Banyumas Regency during the Covid-19 Pandemic" Journal of World Economy: Transformations \& Transitions (JOWETT) 1(03):10. DOI: https://doi.org/10.52459/jowett13101221

\begin{abstract}
The Covid-19 pandemic has had an impact on various economic sectors in Indonesia, and consequently on Micro, Small, and Medium Enterprises (MSMEs) which have faced a decline in sales figures. The pandemic has forced MSME actors to reorganize their business strategies. Several MSMEs that could survive the impact of Covid-19 in Banyumas have implemented Technology-Based Financial Management which includes the use of software in managing their financial data so that MSME actors are able to calculate, manage, budget, predict expenses and profits to be achieved. The long-term goal of this research is to enrich the development of science, particularly, to examine bounded theory as the dominant factor influencing the intention of MSME actors in using financial software. Further, this research analyzes whether the financial software developed by the research team could help the process of MSME operational activities and has an impact on the sustainability of MSMEs during the Covid-19 Pandemic. Data collection for this study was carried out by distributing questionnaires through online media to MSME actors in the Banyumas Regency who were respondents and a direct approach to MSMEs concerning the use of financial software. The random sampling technique has been applied for this research, meanwhile, for data analysis the Statistical Product and Service Solution (SPSS), version 22.0, has been used. The expected results from this research may help to analyze and provide empirical evidence that bounded theory is the dominant factor influencing the intention of MSME actors in using financial software. The output of this paper can contribute to knowledge, especially regarding the implementation of financial software and theory development.
\end{abstract}

\section{KEYWORDS}

Bounded Rationality Theory, Financial Software, Sustainability, MSME, Covid-19 Pandemic, Indonesia 


\section{INTRODUCTION}

Micro, Small, and Medium Enterprises (MSMEs) have a significant role in the economic development of a country (Audretsch, Thurik, 2004). The existence of MSMEs, when viewed more closely, is believed to be able to contribute to poverty alleviation efforts with the absorption of labor (Adomoko, et al. 2016). Banyumas Regency, which has a relatively large area, according to data from the Manpower Office for Cooperatives and SMEs, the number of MSMEs in Central Java, especially in Banyumas Regency, reached 84,350 units in 2018. Meanwhile, according to the Central Statistics Agency in 2019, the percentage of MSMEs to the total MSMEs in Central Java was $5.19 \%$.

At the end of 2019, the World Health Organization (WHO) China Country Office reported a case in Wuhan City, Hubei Province of pneumonia whose etiology was not identified. January 7, 2019, the etiology of pneumonia was identified as a new type of coronavirus (coronavirus disease, Covid-19). The COVID-19 case was designated by WHO as a Public Health Emergency of International Concern, and the spread of the number of cases is running fast and spread in other countries. The Covid-19 case was entered for the first time in Banyumas in mid-March 2020, which was followed by the regulation of Large-Scale Social Restrictions or PSBB as a step in accelerating the prevention of Covid-19 transmission. According to the Head of the Banyumas City Resort Police (Polresta), the monitoring is carried out through social quarantine and regional quarantine or can be called "mini lockdown".

Quoting from Media Indonesia (2020) the Covid-19 pandemic has had an impact on various sectors of the country, one of which is the economic sector of MSME which causes a decline in sales figures. The pandemic has forced MSMEs to reorganize their business strategies. The MSME sector at least reduced its stock of goods during the PSBB period by $39.3 \%$ and as many as $16.1 \%$ chose to reduce the number of workers. This is due to a decrease in the number of buyers and changes in the frequency of public spending. In tackling the problems currently faced by MSME actors, the government continues to strive to maintain the existence of MSMEs, among others, by providing government assistance programs through Pre-employment Cards, electricity tariff subsidies, and Family Hope. In addition, the government also helped in reducing tax payments during AprilSeptember 2020 and relaxed and restructured loan payments for MSMEs and cooperatives.

The Covid-19 pandemic has had an impact on MSME actors in Banyumas. Many MSMEs are confused in dealing with socio-economic problems during the Covid-19 Pandemic which caused an increase in the number of unemployed which was doubled. The head of the Banyumas Regency Manpower, Cooperatives, and Small and Medium Enterprises Office, Joko Wiyono, said to the news agency Republika that the initial occurrence of this outbreak made many MSMEs experience difficulties. 
Despite the large number of MSME actors affected, there are still MSMEs that can survive and show their existence in the Covid-19 Pandemic. According to the information obtained, after the initial interview, it is known that entrepreneurs will be more successful if they are equipped with records in running their business, such as recording raw materials, sales results, and the amount of production. In addition to this, another important factor that greatly helps the process of MSME operational activities is Technology-Based Financial Management. Technology-based financial management includes the use of software in managing MSME financial data so that MSME actors can calculate, manage, budget, predict expenses and profits to be achieved.

MSMEs should indeed use technology-based financial management techniques, but in reality, the implementation of the system is not easily accepted and applied by MSME actors. An important obstacle to the successful implementation of a new system is the lack of attention to behavioral factors during implementation. In addition, there are still few studies that have been carried out concerning behavioral factors during the implementation phase of the new system and the influence of the system on satisfaction and performance. The main factor of behavior is an important matter that will result in a decision to accept the implementation of a system, in other words, the concept of human thinking about the implementation of a new system is the main key that can move human behavior to adopt a new system. This is in line with the concept of bounded rationality theory.

Simon's (1997) bounded rationality theory explains why humans fail to think fully rationally. This study intends to examine and analyze whether the use of financial software for MSMEs in Banyumas Regency has been carried out optimally, as well as the dominant factors that influence the intentions of MSME actors in using financial software for MSMEs in line with the concept of bounded rationality theory. In addition, this research will also see whether the financial software developed by the research team may help the process of MSME operational activities so that it has an impact on the sustainability of MSMEs and their surviving abilities during the Covid-19 Pandemic enabling them to overcome various social problems.

\section{THEORETICAL BASIS}

\section{A. Prospect Theory}

Prospect theory is a theory that explains how a person takes decisions under conditions of uncertainty. The substance of prospect theory is a process of individual decision-making as opposed to price formation which is common in economics. This prospect theory originates from research made by Kahneman \& Tversky (1974). They named the person's behavior as risk aversion behavior and risk-seeking behavior. In prospect theory, Kahneman \& Tversky (1981) revealed that a person will seek information first, then several "decision frames" or "decision frames" will be made decision concept. After the concept of a decision is made, a person will make a decision by choosing one of the concepts that produce the greatest expected utility. Prospect theory suggests that people who have an irrational tendency to be more reluctant to gamble gain (gain) rather than loss 
(loss), if someone is in a position profit, the person tends to avoid risk or is called risk aversion, whereas if someone is in a loss position then that person tends to dare to face the risk or is called risk-seeking.

\section{B. Policies related to the Covid-19 Pandemic}

On March 31, 2020, the President of the Republic of Indonesia ordered Government Regulation in Lieu of Law No. 1 of 2020 (PERPU 01/2020) concerning State Financial Policy and Financial System Stability for Handling the 2019 Coronavirus Disease (Covid-19) and/or in the Context of Facing Dangerous Threats. National Economy and/or Financial System Stability. And on April 3, 2020, the President issued Presidential Regulation (Perpes) No. 54 of 2020 concerning Changes in Posture Details and the 2020 State Budget. This Presidential Regulation is a follow-up to Perppu No. 1 the Year 2020.

\section{The impact of the COVID-19 pandemic on MSMEs}

In accordance with Law Number 20 of 2008, the definition of Micro, Small, and Medium Enterprises is as follows "Micro Business is a productive business owned by individuals and/or individual business entities." Small Business is a productive economic business that stands alone, which is carried out by individuals or business entities that are not subsidiaries or not branches of companies that are owned, controlled, or become part either directly or indirectly of Medium Enterprises or Large Businesses that meet the Business criteria. Small."

Based on the information portal "kontan.co.id", it is known that MSMEs are the most sector affected by the Covid-19 pandemic. Based on a survey conducted by the authors, it is known that the culinary sector MSMEs are the sectors most affected by this pandemic. The tourism sector is also affected by the Covid-19 pandemic and revenue from tourism objects has decreased due to the impact of social distancing policies and the lockdown of several places. The data from the Center for Economic Research (P2E) of the Indonesian Institute of Sciences (LIPI) shows that the impact on MSMEs engaged in micro food and beverage businesses (culinary sector) is $27 \%$, on small food and beverage businesses are $1.77 \%$, and on food and beverage medium enterprises are $0.07 \%$.

Despite the large number of MSME actors affected, there are still those that are able to survive and show their existence during the Covid-19 Pandemic. One example is the convection business in Purwokerto, namely Kaos Ngapak. Pujianto as a business owner admits that his business has experienced a five-fold increase in turnover during this Covid-19 pandemic. Therefore, the authors want to analyze the factors that can affect the sustainability of MSMEs during the Covid-19 Pandemic, so that MSMEs can survive during this extraordinary situation and be able to overcome various social problems.

\section{Accounting Software Specifications}


Computer applications or more popularly known as software have various types. Some are used for photo editing, making videos, designs, and also as accounting software. Accounting software is software that is used to record financial activity in and out of the company. The working principle of accounting software is to convert a series of company financial activities into specific modules so that the final results are in accordance with financial reporting standards. Examples of variables used are sales (accounts receivable), purchases (accounts payable), payroll, general ledger, and others. Large-scale companies usually use self-developed accounting software. But it is not uncommon for medium-sized companies and MSMEs to use third parties that offer financial reporting services using independent accounting software. In order to help the development of MSMEs, the Government publishes various free accounting software applications. Supporting software for accounting-based financial management includes SQL Ledger, GNUCash, and Turbo Cash to support MSME operational activities. Various standard accounting software features contain charts including Multi-user, MultiCompany, Multilanguage, Database, Multi-branch, Multi-Currency, Multi Delivery Point, Import and Export Excel Data, AR Module, AP, GL, Stock, Payroll and others.

Financial problems related to this pandemic require MSME actors to manage their finances as well as possible. As a result of disruptions in business finances, it will encourage MSME actors to apply for loans to related institutions. However, some MSMEs are unable to move, due to the low level of financial knowledge so far. They do not make financial reports, even though in applying for loans to banks they are required to have financial statements to convince the borrowers. Using the application of financial management facilitates MSME actors in processing their operational activities.

\section{E. Bounded Rationally theory as an antecedent concept for the use of financial software} applications

Simon's theory of bounded rationality (1997) explains why humans fail to think fully rationally. This is due to, 1. limited ability to obtain information, 2. use of judgmental heuristics. Heuristics are basic rules or shorthand ways that a person uses to simplify the processing of information into memory (the brain). There are two kinds of judgmental heuristics, namely the tendency to base on information in memory (availability heuristics) and the tendency to judge something based on what he already knows (representativeness heuristics). The fundamental principle of cognition states that our actions are determined by mental representations of the situation, not by the situation directly. The implications of the framing effect in making decisions, like any other cognitive activity, all depend on the view of the situation we face ourselves, that is, our perception of the situation that will determine our behavior.

According to Simon, in organizational decision-making, people lie between two extremes. On the one hand, humans as homo economicus are considered to be able to act rationally, for example being able to obtain perfect information to choose the best alternative from various choices in the decision-making process. On the 
other hand, Freud, Laswell, Pareto said that humans are creatures who do things controlled by subconscious desires, instincts, and anxiety. Simon assumes that decision-making is a process where humans are in a position between these extremes. According to Simon, an analysis should aim to "accommodate both reason and feeling" (Simon, 1997). This concept is finally referred to as bounded rationality, which means that humans cannot be rational as economists understand, but humans have good intentions in doing so or in other words within a limited rational corridor.

\section{Research Framework}

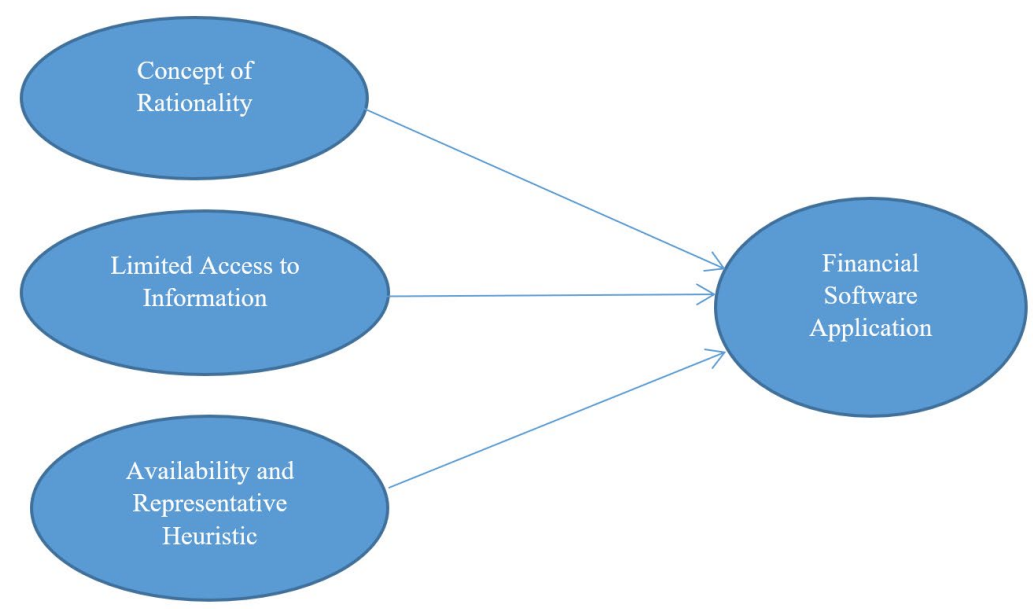

\section{RESEARCH METHODS}

\subsection{Type of Research}

In this research, a quantitative method has been applied which explains phenomena, the participation of researchers is limited because as an effort to avoid bias, the purpose of this study is to test theory and the sample size is large.

\subsection{Research Technique and Population}

In this study, the population is Micro, Small, and Medium Enterprises (MSMEs) in Banyumas Regency, Central Java Province. Samples from the population in this study were taken using the purposive sampling method which represents a method based on certain criteria, i.e. the MSMEs who could survive during the Covid-19 pandemic and have used financial software applications. With the specified criteria, not all of the population in this study can be used as research samples.

\subsection{Data Collection Techniques}


In this study, the technique used by the researcher is by distributing questionnaires to respondents either directly or indirectly. Data were collected through questionnaires sent online to respondents of MSME actors in the Banyumas district. Answers from respondents are then tabulated for analysis.

\section{Hypothesis Testing}

This study has three hypotheses consisting of:

H1: The concept of rationality has positive effects on software applications.

H2: Limitations in obtaining information have a negative effect on financial software applications.

H3: Availability and representative heuristic factors have positive effects on financial software applications.

To test the three above-mentioned hypotheses we use the t-test.

\section{RESULTS AND DISCUSSION}

\section{A. Object of Research}

The object of this research is the sustainability of Micro, Small, and Medium Enterprises (MSMEs) in Banyumas Regency which is influenced by financial management software applications.

\section{B. Research Sites}

The location in this study was conducted in Banyumas Regency, Central Java Province for Micro, Small, and Medium Enterprises (MSMEs). The choice of location in Banyumas Regency was due to a phenomenon related to MSMEs that could survive in the economic downturn caused by the Covid-19 Pandemic.

\section{Respondents Overview}

Research respondents are MSME actors who serve as managers/directors and the finance department. This research was conducted with a quantitative approach using a questionnaire. The distribution of the questionnaire was carried out directly in printed form and indirectly through the google form to MSME actors in Banyumas Regency.

The number of questionnaires distributed to MSMEs is 104 questionnaires for MSMEs actors (individual business persons). Not all of the questionnaires that have been distributed, were returned. A total of 4 questionnaires did not return and another 100 questionnaires were returned. Details of the level of distribution and return of the questionnaire can be seen in Table 1, made by authors: 


\section{Table 1 \\ Distribution and Return of the Questionnaire}

\begin{tabular}{llc}
\hline No & description & Amount \\
\hline 1 & Distributed Questionnaire & 104 \\
2 & Questionnaire that does not return & 4 \\
3 & Questionnaire that cannot be processed & 0 \\
\hline 4 & Total questionnaires that can be processed & 100 \\
\hline & Response rate & $96 \%$ \\
\hline
\end{tabular}

\section{Data Quality Test}

Data quality test includes reliability and validity test. The reliability test was carried out by using the Cronbach alpha test using SPSS. A construct is said to be reliable if it gives a Cronbach alpha value $>0.60$. After testing the quality of the data, it was found that the data passed the validity and reliability test so that it was feasible to carry out testing to the next stage.

\section{Hypothesis testing}

\section{Multiple Regression Analysis}

To determine the effect of the variables of the concept of rationality, the limitations of obtaining information, availability factors, and representative heuristics on financial software applications, multiple regression analysis methods have been used. From the results of the regression test, the results of the equation are as follows:

$$
Y=91,558+0,174 X 1-0,234 X 2+0,411 X 3+e
$$

From these equations, several things can be explained as follows:

1. The constant value is 91.558 , which means that if the variables of the concept of rationality, limitations in obtaining information, availability factor, and representative heuristic are equal to zero, then the financial software application is 91.558 .

2. The X1 coefficient of 0.174 means that the rationality concept variable has a positive relationship with the financial software application variable, this indicates that the increase in 
the rationality concept variable will increase the financial software application variable. If there is an increase in the rationality concept variable by one percent, it will increase the financial software application variable by 17.4 percent, assuming that other variables remain at the 95 percent confidence level.

3. The X2 coefficient of 0.234 means that the variable of limitation of obtaining information has a negative relationship with the variable of financial software application, this indicates that the increase of the variable of limitation of obtaining information will decrease the variable of application of financial software. If there is an increase in the limitation of obtaining information by one percent, it will reduce the financial software application variable by 23.4 percent, assuming that other variables remain at the 95 percent confidence level.

4. The X3 coefficient of 0.411 means that the availability factor and representative heuristic variables have a positive relationship with the financial software application variable, this indicates that the increase in the availability factor variable and the representative heuristic will increase the financial software application variable. If there is an increase in the availability factor and representative heuristic variables by one percent, it will increase the financial software application variable by 41.1 percent, assuming that other variables remain at the 95 percent confidence level.

The results of multiple linear regression calculations obtained an R Square value of 0.201 . These results indicate that $20.1 \%$ of the variation in changes in the financial software application variable (Y) is influenced by the rationality concept variable (X1), the limitations of obtaining information (X2), and availability and representative heuristic factors (X3), while $79.9 \%$ others are influenced by other variables or factors outside of this study.

\section{T-test}

To determine the partial effect of the rationality concept variable (X1), the limitations of obtaining information (X2), and the availability and representative heuristic (X3) factor, the t-test was used on financial software applications. From the results of the analysis using the error rate $(\alpha)=0.05$, it is known that the t-table value is 0.590 . After the T-test, the results of the analysis are as follows:

\section{a. The influence of the concept of rationality on financial software applications}

Based on the results of data analysis, it is known that the influence of the concept of rationality affects financial software applications. This indicates that the higher is the rationality of MSME actors towards the benefits of financial software applications, the more influential it will be on the acceptance, use of financial software applications in MSME financial management in Banyumas Regency. MSME actors in Banyumas Regency feel that the ease of learning and using financial software applications can provide 
convenience in efforts to manage their business finances. The perceived convenience affects increasing the confidence of MSME actors in Banyumas Regency in using financial software applications. The results of this study are in line with the concept of bounded rationality theory that has been carried out in the research of Matsumoto et. al (1996).

\section{b. Effect of limitations in obtaining information on financial software applications}

The results of data analysis show that the limitations of obtaining information have a negative effect on financial software applications. Based on Simon's theory of bounded rationality (1997) one of the contributing factors to humans failing to think rationally is limitations in obtaining information. The results of this research also support good research by Loke (1989), Li et.al (2008), Hampton (2005). These results are in accordance with the facts on the ground that happened to MSME actors in Banyumas Regency. In the majority, MSME actors in Banyumas Regency MSMEs do not understand what a financial software application is, so there is a need for the socialization of financial software applications. MSME actors do not fully understand that the application of financial software applications in the preparation of MSME financial reports will provide various uses for business management. One of them is the ease of obtaining capital from external parties (financial institutions) and investors. The limitations they get regarding financial software applications will hinder the process of implementing financial software applications.

\section{c. The influence of availability and representative heuristic factors on financial software applications}

Based on the results of data analysis, it is known that the availability and representative heuristic factors affect financial software applications. This is in accordance with Simon's (1997) bounded rationality concept which explains the use of judgmental heuristics. The results of this study are also in line with research conducted by Cheng et.al (2010), Lee (2004), O'Donnel (2000), and Orgad (2011). Heuristics are basic rules or shorthand ways that a person uses to simplify the processing of information into memory (the brain). There are two kinds of judgmental heuristics, namely the tendency to base on information in memory (availability heuristics) and the tendency to judge something based on what he already knows (representativeness heuristics).

The tendency of availability and representative heuristics for MSME actors in Banyumas Regency will support the acceptance of the financial software application process, the higher the perception of availability and representative heuristic tendencies for MSME actors in Banyumas Regency as users of financial software applications, the higher the positive attitude to use financial software applications. owned by the MSME. MSME actors in Banyumas Regency feel that the ease of learning and using financial software applications can provide convenience in efforts to manage their business finances. The perceived ease has an effect on increasing the positive attitude of MSME actors in Banyumas Regency 
in using financial software applications. The results of this study support the research concept of Simon's (1997) bounded rationality.

\section{CONCLUDING REMARKS AND RECOMMENDATIONS}

\section{Conclusion}

The conclusions of this study are as follows:

1. Theoretically, the research results prove that the research concept uses;

2. The concept of bounded rationality theory is proven to have an effect on the intention to use financial management software on partner SMEs in Banyumas Regency. The results of this study support the concept developed by Simon (1997.)

3. The application of financial management has a significant effect on the sustainability of MSMEs. This shows that the financial management application owned by MSME actors if it gets better will encourage business continuity during the Covid-19 pandemic.

\section{Suggestion}

1. For MSME players, it is hoped that they will be able to understand better financial management applications in order to be able to maintain business continuity, especially during the Covid-19 pandemic.

2. The Department of Manpower, Cooperatives, and MSMEs are expected to be able to provide education or training to provide and improve MSME actors related to financial management applications so that MSME actors are able to maintain their business continuity.

FUNDING: The authors did not receive any external funding.

CONFLICT OF INTEREST: The authors declare no conflicts of interest.

\section{REFERENCES}

1. Adomako, Samuel; Danso, Albert; Damoah, John Ofori (2016). The moderating influence of financial literacy on the relationship between access to finance and firm growth in Ghana, Venture Capital, 18:1, 43-61. https://doi.org/10.1080/13691066.2015.1079952 
2. Audretsch, D., \& Thurik, A. R. 2004. A model of entrepreneurial economy. International Journal of Entrepreneurship Education, 2(2): 143-166. Available

at: https://www.researchgate.net/publication/45128378_A_model_of the entrepreneurial economy

3. Cheng, F.-F., dan C.-S. Wu. 2010. Debiasing the framing effect: The effect of warning and involvement. Decision Support Systems, Vol. 49, No. 3, pp.: 328-

334. https://doi.org/10.1016/j.dss.2010.04.002

4. Hampton, C. 2005. Determinants of reliance: An empirical test of the theory of technology dominance. International Journal of Accounting Information Systems, Vol. 6, No., pp.: 217240. https://doi.org/10.1016/j.accinf.2005.10.001

5. Irwandi, Sony. 2019. Determinan intensi investigasi dalam mengungkap fraud, Persepektif auditor internal pemerintah. Disertasi. Tidak dipublikasikan.

6. Li, X., T. J. Hess, dan J. S. Valacich. 2008. Why do we trust new technology? A study of initial trust formation with organizational information systems. The Journal of Strategic Information Systems, Vol. 17, No. 1, pp.: 39-71. https://doi.org/10.1016/j.jsis.2008.01.001

7. Lee, J. D., dan K. A. See. 2004. Trust in automation: Designing for appropriate reliance. Human Factors: The Journal of the Human Factors and Ergonomics Society, Vol. 46, No. 1, pp.: 5080. https://doi.org/10.1518\%2Fhfes.46.1.50 30392

8. Loke, W. H. 1989. The Effects Of Framing and Incomplete Information on Judgments. Journal of Economic Psychology, Vol. 10, No.3, pp.: 329-341. https://doi.org/10.1016/0167-4870(89)90028-7

9. Matsumoto, D., T. Kudoh, dan S. Takeuchi. 1996. Changing Patterns of Individualism and Collectivism in the United States and Japan. Culture \& Psychology, Vol. 2, No.1, pp.: 77107. https://doi.org/10.1177\%2F1354067X9621005

10. O'Donnell, E., dan J. David. 2000. How information systems influence user decisions: a research framework and Literature review. International Journal Accounting Information System, Vol. 1, No.3, pp.: 178-203. https://doi.org/10.1016/S1467-0895(00)00009-9

11. Orgad, M. S., dan M. Toledano. 2011. Strategic framing: indigenous culture, identity, and politics. Journal of Public Affairs, Vol. 11, No. 4, pp.: 325-333. Available at: https://www.academia.edu/23260442/Strategic_framing_indigenous_culture_identity_and_politi $\underline{\mathrm{cS}}$

12. Simon, H. A. 1997. Models of Bounded Rationality. Massachusetts: The MIT Press.

13. Tversky, A., dan D. Kahneman. 1974. "Judgment under Uncertainty: Heuristics and Biases". Science, New Series, Vol. 185, No. 4157, pp.: 11241131. https://doi.org/10.1126/science.185.4157.1124

14. Tversky, A., dan D. Kahneman. 1981. "The Framing of Decisions and the Psychology of Choice". Science New Series, Vol. 211, No. 4481, pp.: 453-458. https://doi.org/10.1126/science.7455683 